\title{
The Discursive Construction of Anti-European Sentiment in the times.co.uk Texts
}

\author{
Roberto A. Valdeón \\ University of Oviedo \\ valdeon@uniovi.es
}

\begin{abstract}
The critical study of language has payed particular attention to the discursive construction of concepts such as national identity, ideology or hegemony. In this paper we applied Fairclough's three-dimensional model of CDA to the presentation of European matters in the online texts of The Times, a mass medium noted for its traditional alliance with the British political and economic establishment, analysing the discursive strategies used by text producers in the headlines, leads and stories of 84 reports, opinion articles and editorials in an attempt to identify the ideological components imbued by the text producers and, thus, establish the degree of impartiality towards the European issue and whether the discourse used by this mass medium is an example of the traditional British resistance towards EU integration.
\end{abstract}

\section{Introduction}

The critical study of discourse has produced an impressive amount of work by reseachers in the last years of the $20^{\text {th }}$ century, particularly after the emergence of Critical Discourse Analysis (CDA), which aims not merely at describing the linguistic patterns of texts but also at determining the connections between power, ideologies and the texts themselves (Fairclough, 1992a: 12; Georgakopuolou \& Goutsos, 1997: 10). Fairclough presents it as "discourse analysis which aims to systematically explore often opaque relationships of casuality and determination between (a) discursive practices, events and texts, and (b) wider social and cultural structures, relations and processes" (1995b: 132). CDA is, thus, 
concerned with social and political problems of discourse in general, and, very often, the discourse of news media in particular. One of the advantages of the critical approach to news reporting is that it helps expose the damaging assumptions made by the media as regards ideology, production and audience (Davis, 1985: 58). A number of researchers have worked within this area in recent years (van Dijk, 1990, 1996, 1998, 2003; Fowler, 1991; Bell 1991, 1998; Fairclough, 1992a, 1992b, 1995a, 1995b, 2001) in an approach that boasts its flexibility as one of its main assets (Fairclough, 1992b: 226; 1998: 144; Beaugrande, 2000: 101-102; van Dijk, 2003: 144).

In this paper, we shall resort to Fairclough's proposed CDA model to analyse the linguistic strategies used by journalists (who, using Fairclough's terminology, will also be referred to as text producers) in the presentation of the European issue during 2004 at a crucial time for the future of the Union, due to two key events: the accession of ten new countries to the club, which represented the biggest enlargement in its history, on the one hand, and the negotiations to approve a European Constitution while the British cabinet decided to call a referendum on the issue, on the other. For this purpose, we have selected the reports, opinion articles and editorials published on the online version of The Times newspaper, traditionally regarded as the voice of the political and economic establishment in the UK. At the moment, the newspaper belongs to News International, one of the world's five biggest entertainment and news conglomerates (McChesney, 2000: 59). The corporation is owned by Rupert Murdoch, who has been regarded by some as the Hitler of the media moguls (67).

Fairclough's three-dimensional approach to the analysis of communicative events features text, discourse practice and sociocultural practice (1992b; 1995a; 1995b; 2001). In the present analysis the texts are written taking the form (or genre) of media articles, and the discourse practice refers to the production and subsequent comsumption of the texts. This actual production process will involve correspondent reporting from Brussels and/or use of agency dispatches. Finally, sociocultural practice will relate the previous two sections to the situation of Britain, as a country which has traditionally shown a strong reluctance to advance in the construction of the European Union whenever there entered questions of sovereignty and cultural identity, as when they opted to remain out of the euro zone or the Schengen area in the past. Consequently, we shall relate the linguistic events to the political situations in which they are embedded.

As regards the first dimension, we shall cover specific forms of linguistic analysis, such as the lexicon or the syntax as well as those features of textual organization that might throw light on the issues being explored. Drawing on Halliday \& Hasan (1976: 26ff), for Fairclough (1995b: 58) texts have three specific functions: ideational (related to the representations and recontextualizations of social practice, such as carrying particular ideologies), interpersonal (particular constructions of writer and reader identities) and textual (particular constructions of relationships between them, such as degrees of closeness or familiarity). In his model, these functions can be examined by means of ten questions (plus a number of complementing sub-questions) as regards their vocabulary, grammar and structures (2001: 92-100). Due to the specific nature of this study and the discourse type 
we are concerned with, we shall concentrate on those that might be of special interest for the discussion of the ideological implications, such as those related to the expressive and experiential values of the lexicon, the ideological function of significant meaning relations or the use of certain linguistic processes. Thus, rather than answer the questions in Fairclough's model, we shall concentrate on the following aspects:

-Transitivity, a process noted by Halliday as being capable of offering "different encodings" of the same "state of affairs"(1985: 322), has been regarded as a strategy capable of allowing writers to consider several ideological possibilities and use those that may benefit their own positions and suppress those that do not (Fowler, 1991: 70).

-Nominalizations have been taken as a feature of the transitivity process (Fairclough, 1992b: 177-185, also drawing on Halliday, 1985: 101ff) and also as a fundamental strategy to imbue ideological content to the construction of the text.

-Speech reporting will also be covered. This strategy allows text producers to carry out transformation processes that may change the actual words used by speakers and/or other writers, and, consequently, alter their implications (Halliday, 1985: 227-235; Fairclough, 1995b: 54-69).

-Modality will be focused upon, since it is a process that allows the text producer to communicate different degrees of agreement or disagreement with the propositions being expressed (Fowler, 1991: 85-87; Fairclough, 1992b: 158-162).

We shall also deal with the lexical choices in the articles, since these allow text producers to infuse their work with their own representation of the world (Fairclough, 1995b: 133-114; Clark \& Ivanic, 1997: 63; van Dijk, 1996: 9-12; van Dijk, 1997: 162-166).

This takes us directly to the second dimension, or discourse practice, since editing processes are connected with the likely interpretation(s) of the texts. Fairclough offers a two-fold approach consisting of institutional processes (such as editorial routines) on the one hand, and discourse processes (affecting transformations in production and consumption) on the other (1995b: 59-61). As he points out, "participants in any discourse operate on the basis of assumptions about which (series of) discourses the current one is connected to, and their assumptions determine what can be taken as given in the sense of part of common experience, what can be alluded to, disagreed with, and so on" (2001: 121). In the case of the texts we are about to analyse, we shall consider the way in which text producers and text consumers interact in their interpretation. We shall also consider another aspect in Fairclough's framework affecting interpretation: the extent to which the lexical choices in the texts inform us on whether we are confronted with what Fairclough terms "conventional discourse practice" or "creative discourse practice" (1995b: 60), that is, whether the discourse practice in media writing as regards the issue in this paper is homogeneous in forms and meanings or whether it might manifest the nature of change in society.

Finally, we come to the third dimension, which Fairclough also calls explanation (2001: 135), that is, sociocultural practice. This level may involve a range of aspects that constitute social and cultural practice, including economic, political, historical, religious, 
etc. In this paper we shall be more concerned with those political aspects that could inform us on societal connections between text and interpretation of texts. In this sense we are concerned with deciding on whether text producers use their positions of power to exert an influence on the elements of the discourse, whether these have an ideological character and on the nature of the (likely) struggles between the participants (2001: 138). For this section we shall resort to the definition of ideology as a set of assumptions accepted by the participant(s) in a given stretch of discourse (Simpson, 1993: 5; Fairclough, 2001: 2). Gramsci's definition of the concept of "hegemony" (1971:12) may also prove valuable in the discussion.

Let us now move on to explicit the objectives and the methodology used in the analysis of the texts. Although Fairclough stressed that his model had been initially conceived to carry out the comprehensive study of single texts (1992b: 225ff), the approach can certainly be applied to a corpus of texts belonging to the same order of discourse in order to examine, as suggested by Wodak (2003: 17-34) and by Fairclough himself (Chouliaraki \& Fairclough, 1999: 59ff), a number of secondary issues that may inform us on the central topic under scrutiny. For this purpose we propose to cover a total of 84 texts published on the website of The Times, www.timesonline.co.uk, over a six-month period (December 2003-May 2004). We have chosen this specific news medium because its traditional alliance with the British establishment, both economic and political, could offer an interesting insight into the existing gap between the traditional resistence in the UK towards achieving greater integration with its European counterparts, and the more pro-European position held by the current government. These are the objectives of the paper:

1. We shall analyse the textual strategies present in the articles in order to ascertain what political positions are particularly favoured and, therefore, whether there are indications of a clear editorial policy as regards European issues.

2. Bearing in mind the connections between the Labour government and the current owner of The Times (Cohen, 2004) and the newspaper's more traditional views on Europe, we shall analyse whether there are instances of "creative discourse", that is, whether certain "voices" within this medium could signal a change towards closer links with Europe, even if the predominant editorial strategy aims at supporting some degree of independence from Europe.

3. Consequently, we shall attempt to define the discursive strategies present in the articles and the objectives as regards the interpretation that text consumers might make, and whether the text producers-text consumers relationship is of a symmetrical or asymmetrical nature.

In the next sections we shall cover the three parts into which newspaper texts are divided, headline, lead and story proper (Bell, 1991; Fowler, 1991; Bell, 1998), applying the textual and interpretative dimensions of Fairclough's CDA model to each element. In a final section, we shall pursue a discussion on an explanation for our findings by bringing the arguments in the previous three sections together. We first turn to headlines. 


\section{Headlines}

Transitivity, the strategy that permits text producers to make decisions on the focus of the participants within the clause (Halliday, 1985; Fairclough, 1992b: 178), is concomitant with the informative nature of headlines, their aim being to attract the attention of the reader towards the text. Transitivity does not correspond exactly to the same notion in traditional grammar, where it refers to a syntactic relation. In a more functional approach, it also encompasses an important semantic component (Fowler, 1991: 70-71). In this sense, headlines do not function merely as summaries of the stories being reported but as "promotional" phrases or clauses, likely to be imbued with ideological implications derived from the choices made by text producers. In the corpus, headlines tend to show 'directedaction' processes (Fairclough, 1992b: 180), which imply a subject acting upon a goal. Very often the subjects (or actors in Halliday's, 1985: 30-33, 109-112, and Fowler's terms, 1991: 71) are European leaders or nations, pictured as aggressive with regard to the British government or to their role in the future of the EU,

1.a. Leaders challenge Blair over EU constitution (09/02/04).

2.a. Brussels plans to expand its empire again (04/05/04).

3.a. Spain and Poland could kill new EU deal (17/05/04).

In other cases they are portrayed as performing 'mental' processes. In these cases, text producers opt to present European groups, whether they are nations or socialist parties, as influenced by the changing position of the British government as regards the European constitution. This position is reinforced by the choice of actor in Example 4.a. In this headline, the breach between Britain and the rest of Europe goes well beyond the limits of party politics and reflects a nationwide concern, since the writer stresses the existing gap between the British Labour government and their Socialist counterparts:

4.a. EU socialists fear threat of a British 'no' vote (23/04/04).

5.a. EU allies revive hopes of deal on constitution (17/03/04).

Even when the news headline introduces a more optimistic view, that of the British Foreign Secretary with respect to the referendum, this is toned down by introducing a critical remark that weakens the position of the government:

6.a. Straw predicts victory despite Labour's referendum disarray (23/04/04).

7.a. Blair hints at second EU vote if he loses (22/04/04).

8.a. Party line 'has no place in EU vote' (04/05/04).

The strategy of undermining the government's position on the EU constitution is present in other headlines, notably in those that are presented as either direct or indirect speech. Fairclough has noted the ambivalent role that these two modes of discourse play in media reporting (1995a: 55-56) since indirect speech, or discourse, would allow the text producer 
to intervene in the primary discourse or direct speech. Consequently, the distinction between primary and secondary discourse becomes less obvious, and the writer can manipulate the former much more easily. In the examples we quote below, the headlines become particularly ambivalent due to two strategies: the use of indirect discourse as well as the absence of inverted commas, which would have marked the words as "verbatim" (Bell, 1991: 61):

9.a. I apologised to Cabinet over EU poll, admits Blair (29/04/04).

10.a. Britain heads Europe's new power bloc, insists Blair (30/04/04).

11.a. Blair pushes for early deal on EU constitution (26/03/04).

12.a. Howard mocks Blair for eating his words (21/04/04).

13.a. Tories say constitution would add to red tape (23/04/04).

14.a. UK poses threat to treat, Chirac says (30/04/04)

15.a. Prodi warns of rearguard position for Britain if vote goes against treaty $(03 / 04 / 04)$

In the first two examples the apparent direct discourse of the British Prime Minister is fronted for emphasis, leaving the reporting verb and the subject for the end. The use of direct speech seems to give prominence to the words of the politician. However, the position and choice of the reporting verbs emphasize the view of the text producer. In 9.a $\mathrm{Mr}$ Blair is portrayed as staging a weak position vis-à-vis his own cabinet. In the second, the use of "insist" also seems to point in that direction as the word indicates a need to reaffirm his views on the EU issue.

The other three headlines are clear examples of indirect discourse, more likely to allow the text producers to transform linguistic structures and lexical choices. Example 11.a seems to imply strength on the part of the Prime Minister, even though that could be the effect of a transformative process by the writer. The other two examples reproduce the conservative opposition's views on two issues surrounding the constitutional debate. The choice of the reporting verb "mock" strengthens the moral stance of the conservative leader and implies a lack of coherence in Labour policies as regards European issues, whereas in Example 13.a the text producer has opted for a more neutral "say" to reproduce the views of the opposition. However, the choice is not necessarily non-partisan since by giving more attention to the primary discourse, text consumers are presented with what sounds like the "voice of common sense" (Fairclough, 1992b: 92; 2001: 64-66): the logical consequence of more regulations from Brussels.

We come, thus, to the last two examples of this series. In Example 14.a we return to direct discourse, this time from a continental leader. The words of French President Chirac are reproduced to emphasize the fact that (some) European leaders regard Britain as an impediment to achieve European integration. It is worth mentioning that the headline relies on the symmetry of the construction for greater effect on the text consumer, with "UK poses" and "Chirac says" given frontal and final positions respectively. Hence a contrasting effect between "Britain" and "Chirac" (representing the Franco-German axis) is achieved, whereas, occupying a middle position, the wordplay with "threat" and "treat", emphasizes the hegemonic role of France and Germany in Brussels. 
In Example 15.a indirect discourse is used again to link negative lexical choices ("rearguard position") with the President of the European Commission. The writer is, partly, interpreting Mr Prodi's words to create the effect of threat in a headline that conveys a wider negative perspective of things European, thanks to the use not only of "warn" as an introductory reporting verb, but also "rearguard" and "against", even if the actor of the story is Britain. However, there is a difference in the choice of subjects for the headline: whereas Prodi is personalized and linked to negative terms such as "warn" and "rearguard" (both directed at Britain), the UK disappears in the if-clause, as it were, as the subject preferred by the writer is "vote". This asymmetric representation of Britain with respect to the European commission might be taken to project the voice of the writer onto the readership (a strategy referred to as "incorporation", Fairclough, 1995a: 58), and, consequently, the readership of The Times will have very few options to carry out their own interpretative procedures of the news event.

We now move to an altogether different pattern: the use of conversationalization strategies in what may be regarded, a priori, as an attempt to establish closer links with text consumers. This shift from the more formal to the more informal/colloquial varieties of the language has been acknowledged by journalists (Howard, 1985: 3-4) and discourse analysts (Cameron, 1995: 33ff) alike as a result of the changes taking place in society itself. However, in the examples below the reasons for the choice of register could hide an ideological bias. Before we analyse the style and attempt an interpretation, let us consider the examples:

16.a. U-turn if you want to, the Prime Minister made a 360-degree spin (21/04/04).

17.a. I've seen the future: it's scary and Belgian (24/04/04).

18.a. Don't answer the European question: vote for Euro-blur (24/04/04).

19.a. Hurrah! With one giant U-turn we are free (26/04/04).

20.a. Fools rush in $(27 / 04 / 04)$.

The conversationalization strategies include the use of informal/colloquial lexicon, the use of contractions as a marker of familiarity, and the use of exclamations and imperatives. These features differ considerably from the previous examples in that the writers address their readership directly. However, this is not surprising since the five examples quoted correspond to either editorials or opinion articles, where the text producers allow themselves to position themselves in favour of or against the issue being discussed in the text, and, therefore, might be attempting to influence the readers. Let us now consider them in some detail. Example 16.a uses the metaphor favoured by the British media to refer to Mr Blair's change concerning the European constitution, "u-turn", in a conditional sentence that reflects the vulnerability of the Prime Minister's position by using the colloquial "if you want", impressing the view that political decisions could be taken without too much consideration. However, the most remarkable strategies come in the other quotes. In Example 17. a readers are lured into reading the text by using the first person singular, that is, the voice of the writer, as a marker of experience and, 
consequently, knowledge. This "voice of experience" is then projected into the future to identify it with the issue of European integration, represented by "Belgian". This would have already explicited the concerns of the text producer without any additions. However, there is a clear option for adding a more personal view, not necessarily based on experience, as "Belgian" is preceded by "scary". The position of the two attributes is also indicative of the writer's concerns: the warning is prioritized over the more factual "Belgian".

The next two examples follow the same line, although with one important difference. In 18. a the readership is directly instructed on the approach to Europe. The position of the British is not merely presented as one of rejection, but of total indifference, since the negative imperative is not aimed at imposing ways of action, but rather ways of inaction. This sentence is paralled by another imperative, this time in the positive. Once again the imperative does not attempt to move the readership to perform action with respect to the European issue but rather to remain inactive, since the pun on "Euro-blur" identifies the changing and unstable position of the Prime Minister, and, therefore, calls for remaining cautious.

In Example 19.a, on the other hand, the writer opts for an unequivocal positioning against the European issue. The headline opens with a tabloid expression of satisfaction, the exclamation "hurrah!", to be followed with a sentence that focuses, once again, on the fragile position of Prime Minister Blair, emphasizing the extent of the change by means of the adjective "giant". End-focus is consciously placed on "free", the implication being that the previous situation was constraining freedom in the UK, whether that might refer to Brussels or to the Prime Minister's stance is irrelevant since the point is to stress national identity. Finally, the headline has recourse to another device characteristic of media texts, the use of inclusive "we" to involve text consumers in the acceptance of the views expressed by the writer (van Dijk, 1990: 243; Fowler, 1991: 188-89; Fairclough, 1995a: 77; Clark \& Ivanic, 1997: 30). Some writers claim that "headline content and syntactic structure systematically favour 'us' and problematise 'them'" (van Dijk, 1996: 93-94). In this example the strategy not only favours "us" (understood as Britain) but also victimizes "us" in the struggle to defend national identity (understood, in this case, as political and economic institutions). Brussels, on the other hand, is pictured as imposing its (alien) rules. This keeps in tone with 17.a and other headlines quoted below.

Before moving to the next feature, it is worth underlining, then, that these conversationalization strategies (Examples 16.a to 20.a) rely more openly on linguistic patterns capable of involving, and therefore attracting, the readership. Consequently, the informal features we have commented upon do not necessarily reflect a shift from older editorial routines to "fresher" more modern approaches to language. They would indicate changing practices in order to manipulate the targeted readership. In this sense, text consumers must be alert to distinguish between practices aimed at democraticizing society and those aimed at exerting power and imposing ideological positions upon the readers (Fairclough, 1995a:78-80).

Nominalizations have been noted for their ideological implications and, as mentioned 
above, have been identified as a feature of transitivity processes (Fowler, 1991: 80ff). For our purposes we deal with them separately since heavy noun phrases standing on their own are also characteristic of English headlines. Drawing on Halliday \& Hasam, Fowler suggests that this process is mystificatory in nature allowing text producers to cover up the relations of power between them and the consumers as well as their attitudes with respect to the ideological components underlining the texts (1991: 80). This strategy is favoured in headlines because nominalizations are more economical (Swan, 1995: 359-361), but also because they tend to focus on a particular interpretation of the news event. The headlines in the corpus are remarkable in this sense:

21.a. Blair's crusade for European constitution (27/02/04)

22.a. Britons in new poll blow to EU treaty $(08 / 05 / 04)$

23.a. Franco-German attack on Britain over constitution (18/05/04)

The lexical choices preferred by writers denote a struggle between contrasting forces: "crusade", "blow" and "attack". In the first one, the use of the genitive case offers a representation of Tony Blair's European policies as a one-man effort, isolated from his own countrymen. This process positions the Prime Minister as isolated from the inclusive "we" used in a previous headline. He is pictured as an individual, rather than as the representative of his nation, carrying out his personal quest, equated to an inspirational experience, rather than a rational one. In the other two, we return to the inclusive "we", although with two different functions. In Example 22.a, the text producer gives voice to the doubts concerning a EU agreement, thus patronizing the likely readership, whereas in Example 23.a the opposition "we/they" is expressed by means of "Britain" and "FrancoGerman" respectively. The latter modifies the head of the noun phrase, "attack", disguising a disagreement between European allies as an aggressive move by France and Germany. The writer clearly indulges intertextually on previous articles or reports portraying these two nations as a threat to British identity. It is worth noticing the way in which different texts from the same news medium resort to the use of "the language of aggression" (or "militarization of discourse" in Fairclough's words, 1992b: 195) with two different functions depending on the intended effect. Thus, whereas "blow" supports inclusive "we" by stressing the British determination to defend their identity, "attack" portrays the other two nations negatively.

Finaliy, let us turn to other strategies present to a lesser extent in the headlines analysed. Modality is another common feature of news media texts that allow the text producer to show what Fairclough, following Hodge and Kress (1988: 123) and Halliday (1985), calls "affinity" to the propositions (1992b: 158). Modality can take the form of "modal verbs", but not exclusively. In any case, the surprising fact about the headlines examined is the absence of virtually any degree of modality, except in Example 24.a "Big day for Union may also be its high-water mark" (01/05/04). Text producers produce representational political figures or concepts in their headlines, aligning themselves with one of the positions explicited. This Manichaean approach to the European issue, 
discursively constructed through lexical, grammatical and syntactic choices, leaves very little room for other nuances, and when they occur, as in Ex. 24.a it is to express doubt over the benefits of the enlargement of the Union.

We should also mention, before concluding this section, the use of metaphors. We have already seen some cases above (as in the last three examples commented upon), but we now turn to three particular cases with different significance for the issue of the construction of Europe:

25.a. European dinner will test appetite for a constitution (18/02/04)

26.a. EU constitution is back to haunt Blair (26/03/04)

27.a. Dawn breaks over the new Europe (01/05/04)

In the first example there is an obvious tendency towards frivolity. Much of the criticism made against European policies is the never-ending agenda of meetings and summits that often end up in failure, very likely to be regarded as the result of a policy of spendthrifts, of living off the tax-payer. The metaphor used here derives from this image by resorting to two nouns that emphasize the officiousness of many of those meetings, presented here as irrelevant. This frivolity is then linked to the issue that has dominated the European pages of the newspaper over the past year, the European constitution. In the second example, we return to the negative presentation of the same topic, this time conjuring up popular images of witchcraft to project a negative image onto the readership. The charter appears as the actor of the headline whereas the Prime Minister is portrayed as the affected participant, the "patient" in Fowler's terms (1991: 75). In the third example, published on the day the ten new members joined the EU, the metaphor "evolves" around the challenges and hopes of a renovated Europe ("dawn"), but it is tinged with a negative nuance in the choice of the collocation "dawn breaks".

We shall conclude this section with the only headline that deviates from the discursive representations seen so far. In Example 28. a "How ten new members can help us change Europe" (30/04/04), we come across the only instance where the text producer clearly hints at a positive dimension of a EU formed by 25 members instead of the previous 15 . There is not, however, an overenthusiastic tone in the careful phrasing, which seems to introduce the readership to the benefits and duties of an enlarged Europe, although one remarkable feature differentiates this headline from the rest: it is the only instance where the writer uses inclusive "we" to refer to the EU and Britain, or rather to Britain as another member of the EU. There is nothing surprising about this fact, though. The producer of this text is, in fact, Tony Blair.

\section{Leads}

Following headlines, leads are used to introduce the news events properly. Leads have also been referred to as "abstracts" (Bell, 1998: 67), since they introduce the participants in the 
story as well as the action and/or setting, but they can be much more than that. As a followup to the headline they can clarify the content of the story proper when it remains opaque, or when the readers are not familiar with intertextual references to previous news events and texts. Therefore, they can contribute to set the tone of the article. Leads are characterisitic of reporting rather than of opinion articles, whose ideological content is taken for granted and requires no introduction apart from the headline, although, as we shall see, opinion article producers may also use them to strengthen their starting positions. Other relevant features to be mentioned include the fact that leads cannot be necessarily taken as part of the story that follows (van Dijk, 1990: 83), that the structure is not necessarily linear in that text producers may resort to different degrees of discontinuity in time (Bell, 1998: 97) and that they usually contain a reference to two events rather than one (Bell, 1991: 180-181).

For this section, we have selected a small number of quotes. Firstly, it should be indicated that, due to the economical nature of online reporting, leads do not seem to be considered as an essential part of the text and are often omitted. Thus, the corpus is reduced considerably and our selection is based on two factors: whether the lead is physically presented as separate from the story proper (by using, for example, a different colour or by dividing it from the rest of the text with the name of the text producer between lead and story proper) or whether the first paragraph of the article can stand on its own and can be considered separately, without affecting the comprehension of the remaining text, if omitted. The analysis that follows has been divided into two subsections, leads of texts about the European constitution, on the one hand, and on the accession of the ten new members, on the other. The number preceding each example links it to the corresponding headline in the previous section for easy cross-reference, although not all the headlines will have a matching example. Let us begin with the first group.

9.b. TONY BLAIR admitted yesterday that he had apologised to the Cabinet over the way the announcement of a referendum on the European constitution had been handled.

12.b. MICHAEL HOWARD taunted the Prime Minister for changing his mind on a referendum on the EU's constitution as he made clear that the Conservatives would help to lead the campaign for a "no" vote.

13.b. RED tape will soar if Britain approves the European Union constitution, the Conservatives claimed yesterday.

14.b. BRITAIN could be forced to leave the European Union if its voters reject the proposed new constitution in a referendum, President Chirac suggested yesterday.

15.b. BRITAIN will be left behind in a two or three-speed Europe if it rejects the European Union constitution in the referendum promised by Tony Blair, the President of the European Commission said yesterday.

19.b. Giscard's position on the constitution was a gamble - a very foolish gamble. And it hasn't come off.

23.b. The attack came during a fractious meeting of $E U$ foreign ministers in Brussels that ended with Jack Straw, the Foreign Secretary, admitting that negotiations to agree the constitution could fail for the second time in six months. 
The seven quotes above are characterized by the use of indirect speech, except in the case of 19.b, where the evaluative voice of the text producer supersedes the informative content. Example 9. a provides us with the only lead where the readership will not necessarily meet the expectations of the headline, which, seemed to imply, let us remember, that the Prime Minister had admitted to a mistake as regards the issue of the referendum. In the lead, the accurate content is clarified as we are informed that the apology referred to the method in which the referendum was announced rather than to the referendum itself. The writer has resorted to one common news media strategy, information omission or deletion (van Dijk, 1990: 70; Bell, 1991: 70-73; Fowler, 1991: 78). In this case, the omission to why Tony Blair apologised can be readily taken as being ideologically-motivated, since readers are not likely to comprehend the storyline until they have read (part of) the text. The clarification consequently reinforces the view that the text producer has prioritised his own voice and has consciously used this omission to create an ambivalent effect in the headline.

Examples 14.b and 15.b develop the "vocabulary of aggression" used by Presidents Chirac and Prodi, as presented in 14.a and 15.a. The former expands the headline to convey the value of a threat, even if modulated by the modal verb "could" and the reporting verb "suggest". The writer, however, may have incorporated his voice in the lead, since he has opted for indirect discourse and, consequently, the precise words are not reported. As a matter of fact, the story maintains this mode throughout and Chirac's threatening words will not be quoted in the story proper either, where the only direct quotation is: "I am not against the idea of using methods of friendly pressure with countries that are refusing the constitution because that blocks all the others". With these words, the French President seems to have been particularly careful not to make abrupt suggestions. In fact, his approach to the issue has been constructed tentatively; firstly, by using local negation, secondly toning down the choice of "pressure" by means of the premodifying adjective "friendly", and, finally, justifying his position by referring to those who may obstruct the process. In fact, the suggestion that Britain could be forced out of the EU is not expanded in the text in any way. This is also characteristic of leads, because, as Bell points out, they often include information that will not "resurface" in the body (1991: 84). However, the use of this piece of "additional information" seems to respond to the need to infuse the text with presupposed ideological content.

This ideological positioning is supported intertextually over the period of time under examination by leads $12 . \mathrm{b}$ and 13.b. In the first case, the writer gives initial focus to the Conservative leader Michael Howard, who is represented as the actor of the event, whereas Tony Blair is pictured as the patient. The action being represented takes the form of a reporting verb, "mock", which allows the writer to infuse his own interpretation of the action. Howard's focal position within the sentence is reinforced by providing the readership with more precise indirect discourse. Although a clearer reference to his actual words is made this time, the interpretative voice of the writer remains in the choice of the reporting phrase "made clear". Thus, the sentence opens with Howard and culminates with a clear "no" vote. Embedded in this circular structure, Tony Blair occupies a central position between "mocked" and "changing his mind", signifying the logical consequence 
of his lack of coherence in the whole process.

In 13.b, The Times readers are presented with another forceful depiction of the Conservative opposition, once again thanks to the choice of the reporting verb, "claimed", and the words being reported. Here text consumers receive a very visual image of the negative impact that a European constitution would have for the UK, by means of two images widely used in news media, "red tape", on the one hand, and "soar", on the other. However, the main body of the article does not mention the actual words used by the Conservatives, which, in fact, clarifies that the "red tape" will affect a very specific group, businesses, and not the British public as a whole. And when asked about the measures the party would take, the text continues: "But Mr Letwin declined, however, to name even a single regulation that a future Conservative government would scrap. He said he wanted to bring a broader structural change in Whitehall rather than focus on specific changes at this stage". That is, the content of the text is inherently evaluative in nature, with no factual information for the readers to judge. The article, which is only 102 words long, performs a very important task within the policy of this news medium, since it functions within allegedly shared assumptions of what Brussels represents for the British as a nation. We shall see this in more detail in the next section.

Finally, Examples 19.b and 23.b are very different stylistically speaking. Example 23.b follows, indeed, a standard structure in news reporting with clear references to "who, what and where" (Bell, 1991: 175-176). It also seems more cautious in tone, although we should bear in mind that the sentence refers to "a Franco-German attack" mentioned in the headline. Thus, the mood had already been established for the use of the "vocabulary of aggression", with "attack" becoming the actor of the item. It is also noticeable that the writer has opted to introduce evaluative items such as the use of the adjective "fractious" and the action verb "ended". Emphasis is achieved with the two adverbials "for the second time" and "in six months". The lead may certainly be informative, but the evaluative element is also present.

On the other hand, what is definitely missing in $19 . \mathrm{b}$ is information. The text producer has chosen a conversational style to approach the readership and lure them to the article. The position is highly critical of the constitution, presented as the construction of an individual, French ex-President Giscard, however relevant in European politics he may have been, and however erroneous this perception could be. The evaluative component is present in the choice of the noun "gamble", and is underlined through the use of the spoken feature of repetition for emphasis, and the addition of "very foolish". Finally, the next sentence and its phrasal verb ("it hasn't come off") reinforce this "vocabulary of common sense", which recaptures the colloquial taste of formulas of the type "I told you". The lead preserves, in effect, the tone of the headline of this opinion article.

To conclude this section, let us consider three leads from articles dealing with the accession of the ten new members:

27.b. The enlargement of the EU has brought fresh hope to millions. Here we look at a group who took the early bus from Warsaw across the Continent in search of prosperity. 
28.b. Enlargement should reinforce liberal economies and the alliance with the US.

29.b. Laura Krzyszczuk, 25, is Polish and works for the Federation of Poles in Great Britain. She has been living in London for 2 years. She tells compatriots thinking of coming to the UK what to expect.

These three quotes are good examples of where the focus lies in most of the texts we are examining. The first one presents two events summarized in two neat sentences, firstly the reference to the new EU, secondly the effects this enlargement is expected to have. Both are equated to the improvement of the economy of the new countries, as can be traced in the noun phrase "fresh hope" and the prepositional phrase "in search of prosperity". The presentation is also impregnated with the theme of the lead by means of a business-like "Here we look..." introduction. Example 29.b acts as a foreword to an article about the life and miracles of a Pole living in Britain. As in the previous case, evaluative elements are toned down by a straightforward factual style. It is formed by three sentences, unlike all other leads in the corpus. Still, for all its informativeness, the article emphasizes the fact that it is the newcomers that will benefit (or are searching to benefit) from the accession rather than Britain itself.

Finally, 28.b is unique in the presentation of the European matter. It also focuses on the economic side of the enlargement and makes a not unexpected call on liberalism as the heart of Europe's economy. However, it is modulated by the use of the modal verb "should" aiming at conveying tentativeness rather than reassurance. The second argument points out the positive effect that the enlargement may have on the relations between Europe and the United States. It is the only text in the corpus where this case is made. Let us remember, nevertheless, that the article was signed by the Prime Minister.

\section{Stories proper}

We shall now proceed to examine the main bodies of the articles. In this section we shall concentrate on the structure given to the texts as well as on very specific linguistic features that could facilitate their interpretation. However, many of the characteristics we have underpinned for headlines and leads can also be traced in the stories proper so the analysis will focus on new information. We shall remark, however, on the linguistic features of the examples quoted below, and shall attempt to establish intra and intertextual links in order to ascertain the underlying ideological component. The section is subdivided into reports, understood as information-based articles, and opinion articles, mainly evaluative in nature, whether they are presented as "editorials" and "opinion articles", or hidden under the rather awkward label of "parliamentary sketches".

\subsection{Informative reports}

There are three different types of texts content-wise. Firstly, seventeen reports portray the 
European Union as an aggressive, ambitious and chaotic institution, incapable of reaching agreement on issues such as the constitution. Certain nations, notably France, Germany, Poland and Spain, seem to be particularly pernicious in this respect, whereas Britain is defending her own traditions and opposing greater beaurocracy. Secondly, fourteen texts portray the Labour Party and the British government as being at the centre of a turmoil, from which they seem incapable of escaping. Finally, twelve texts offer a contrast between the current cabinet and the shadow cabinet. Conservative members are presented as holding strong and unambiguous positions with respect to the European issue. In these cases, the text always concludes with a quotation from a Conservative leader, taking the form either of direct or of indirect discourse. In the remaining articles, two of these strategies are combined. Let us begin with some examples of the first type:

3.c. SPAIN and Poland, the countries that scuppered a deal on the European Union constitution last December, could also dash the chance of an accord next month (...) Tony Blair has defused the constitution debate by promising a British referendum after it has been ratified by Parliament. But many ministers would not be unhappy if it disappeared from the agenda altogether in the near future (...) Spain wants to revive a plan that would require EU decisions to be passed by countries representing 66 per cent of the population. That would give strengthened blocking power to countries such as Spain. The idea would almost certainly be unacceptable to France and Germany.

23.c. GERMANY and France rounded on Britain yesterday, accusing it of using "salami tactics" to extract concessions "slice by slice" on the proposed new European constitution (...) Wlodzimierz Cimoszewicz, the Polish Foreign Minister, was even more downbeat, after three different compromises he put forward were ignored. "If it goes on like that, I would not bet on an agreement," he told journalists.

Example 3.c abounds in a headline that used the "vocabulary of aggression" to present Spain and Poland as the killers of the EU deal by making great demands for their countries, whereas France and Germany remain the main opponents to these demands. The writer stresses the divide between countries within the EU and presents Britain on a standby in the process of negotiation, an image that does not correspond with other reports on the same issue. The text presents the British role thus: "British government sources said last night that it was hard to see how the Poles could now come up with any proposals that would satisfy France and Germany", placing all responsibility for the failure on the other nations. This image of passivity contributes to deepen the differences among the other countries. Spain and Poland continue to be associated with negative verbs such as "scumper" or "dash" whereas France and Germany are pictured as unlikely to compromise. The only direct political reference to the role of the British cabinet is placed halfway through the article, depicting its somehow distant position, as reflected in the series of local negations used within the sentence: "would not be unhappy if it disappeared from the agenda".

The second quotation resorts to the strategy of using the Franco-German axis as a threat to Britain, where France and Germany are the actors and Britain is victimized as the patient of the news item (as it is referred in critical approaches to news writing, Fowler, 1991: 75). 
The metaphor allegedly used by these two countries ("salami tactics") is clearly disparaging of British negotiations, whereas the reporting verbs are clearly evaluative. The article offers a wider range of negative terms in the corpus. They can be grouped around two main issues: the constitutional treaty and Britain's position. The former includes the following terms, which can be labelled as the "vocabulary of failure": "fail", "disputes", "derailed", "unresolved", "collapsed", "endgame", "blow", "downbeat" and "ignore", amongst others, some of these used repeatedly. The British issue, on the other hand, is presented around the words "crucial", "admitted", "denied" or "relief", emphasizing the difficult position of the government. The article concludes with direct speech from the Foreign Minister from Poland, another nation depicted intertextually in The Times as partly responsible for the failure of the talks.

Let us now move on to the second pattern identified, where Britain is clearly viewed as the victim of the negotiation process, and Tony Blair's position, as head of the government, tumbles down:

10.c. With President Chirac of France issuing a warning that Britain could be forced to leave the $\mathrm{EU}$ if voters reject the new constitution in a referendum, Mr Blair controversially and enthusiastically embraces the new entrants. (...) As the Prime Minister struggles to regain his authority John Prescott, the Deputy Prime Minister, has taken on the role of Cabinet "enforcer" with a specific brief to reassert a sense of discipline among members of the Government.

29.c. TONY BLAIR may retire after the referendum $n \mathrm{n}$ the EU constitution, Neil Kinnock, the former Labour Party leader, suggested yesterday.

As poll after poll over the weekend suggested that Mr Blair faced an uphill battle in winning over the public to the EU constitution, Mr Kinnock said it would be understandable if Mr Blair wanted to leave office after what would be "an immensely trying period".

Mr Kinnock, Vice-President of the EU Commission, said: "He's a young man. He will have been through an immensely trying period. It would be human and understandable if in those circumstances he said, 'I'll hang up my boots now'".

Example 10.c emphasizes the interpretation we had made of its corresponding headline, that is, that Tony Blair's alleged direct discourse hinted at the weakness of his position by means of the reporting verb "insist". The information provided in the article unveils the reasons for the Prime Minister's insistence: on the one hand, the threat posed by nonBritish leaders (President Chirac, this time), and, on the other, his own instability within his party and/or government. The text gives final prominence to a "strong Labour man" who "has taken the reins" of the situation and has attempted to reinforce the Prime Minister's position, pointing once again at Mr Blair's weakness.

More interesting is Example 29.c, following the headline "Tony Blair 'may go after EU vote", which has not been commented upon so far. As can be seen the text producer introduces the article by making use of what appears to be direct discourse (as hinted by the inverted commas). The headline, thus, foresees a dramatic turn in Tony Blair's political 
future. Since The Times texts keep predicting his failure to convince the British nation of the need to support a European constitution, the implication is that the referendum will be lost. Nevertheless, his "likely" departure is modulated in the headline through the use of the modal verb "may", apparently used by the source of the information itself. As we read the (very short) article, the utterance quoted in the headline does not appear to have been used by Neil Kinnock, who turns out to be the source. Mr Kinnock's words provide the readership with a personal interpretation of a likely victory of the "no" option in the British referendum. The text producer uses the reported verb "suggested" to start the article with the same words used in the headline, but this time they are clearly presented as indirect discourse. This reporting verb, together with others like "insist", "admit" and "warn", used in other reports of the corpus, seem to be used by text producers as part of their strategy of evaluative interpretation. Following Halliday's discussion on the different representational and inferential values of reported speech (1985: 231-237), these verbs project the standpoint of the writers rather than that of the speakers themselves. These verbs would function as filters through which the writers project their interpretations, sparing the text consumers the chance to draw their own conclusions. In Example 29.c, in fact, $\mathrm{Mr}$ Kinnock's actual words do not seem to suggest that his colleague will retire. He simply indicates that if Tony Blair chose to do so after the referendum, Mr Kinnock would understand it, due to the difficulties the Prime Minister is going through at that moment. Another pertinent feature of this article is the strategy defined as "news actor labelling" (Jucker, 1996). The writer underlines the relevance of his source by using appositions that stress his past and present experience within the Prime Minister's own party ("the former Labour Party leader" and "Vice-President of the EU Commission").

As for the texts included of the third type, they emphasize the problems affecting the Labour government and give voice to different MPs from the Conservative opposition, usually the Tory leader or a member of the shadow cabinet, who receive final prominence in the rounding-off of the article. In the next examples, we quote the opening and closing sentences in order to observe the contrasting effect achieved by text producers:

12.c. The Conservative leader mocked Tony Blair by reminding him of his speech to the Labour Party conference last year, when he declared that he had no reverse gear (...) To laughter from Tory MPs he quoted past statements ruling out a referendum by $\mathrm{Mr}$ Blair and Peter Hain, the Leader of the Commons, who as Europe Minister negotiated early drafts of the constitution. Mr Howard also sought to embarrass Labour MPs, saying that 319 of them voted against a referendum...

15.c. Romano Prodi said that there would be "heavy" consequences if Britons voted against the constitution - the product of 18 months of cross-European debate (...) Michael Ancram, the Shadow Foreign Secretary, said that suggestions that Britain may face ejection from the EU were "scare tactics" to try to persuade people that the referendum was not about the constitution but about staying in or coming out of Europe.

26.c. TONY BLAIR faced renewed pressure over the European constitution last night as Europe's leaders set a June deadline for an agreement, coinciding with elections to the European Parliament (...) 
The Conservatives will hold a Commons debate on the issue on Tuesday. Michael Ancram, the Shadow Foreign Secretary, told The Times: "The European constitution's return has come at a bad time for Labour. The British people will seriously resist being bounced out of their right to decide their own future".

30.c BRITAIN has softened one of its "red lines" on the EU constitution, saying that it is prepared to abandon the national veto on some areas of criminal law to precipitate a deal (...)

The Conservatives indicated their intention yesterday to maximise the Government's discomfort over the constitution. Michael Howard, the Tory leader, said a government led by him would unpick a European constitution.

He said the constitution would be the biggest change since the 17th century to the way Britain governs itself. "This constitution is unacceptable to me and, I think, to a majority of the people in this country," he said.

In 12.c the only perspective presented is that of the Conservative opposition. The headline pointed in this direction through the reporting verb. In the main body, the writer maintains the tone set in that headline by undermining the Prime Minister's position on Europe: the Conservative leader opens up the paragraph and, consequently, the article, and he is to remain the actor of the storyline. In the opening sentence, the writer also introduces the topic, Tony Blair's new policy on the constitutional treaty, and emphasizes the abrupt change. The readership will certainly view the Prime Minister's new position as incongruent with his past statements. However, this picture is definitely one-sided, not only as the result of the tone of the opening sentence. As we proceed, the "language of ridicule" is built upon through other lexical choices, such as "reminded him", "no reverse gear", "to laughter", "quoted past statements", "ruling out a referendum" or "sought to embarrass", producing a distorted picture of the parliamentary debate. It is also noticeable that the writer only uses indirect speech. Thus, Tony Blair's earlier statements have undergone a double interpretation and/or manipulation, since the Prime Minister is indirectly quoted by the Conservative leader, who is also indirectly reported by the text producer. Consequently, Mr Blair's speech becomes not secondary discourse, but tertiary discourse. The last element worth noticing here is the fact the writer has omitted any references to the (very likely) loud reactions from Labour MPs.

Example 26.c follows a very similar pattern, with an opening paragraph depicting Tony Blair at the centre of a political storm orginating in Europe, whereas the second storyline of the article underlines the strong position of the Conservative Party. In this case the Shadow Foreign Secretary's direct speech is given final prominence, whereas the government is merely quoted. Mr Ancram's words underlined the two main arguments used by most Times texts, namely the difficult moment the Labour Party is going through, and the reference to surrendering to Europe's ambitions for an all-powerful Brussels-based pan-European government. His strategy aims at presenting the Conservatives as the only party that speaks for the British, at becoming the only representatives of the "we", while demonizing the Labour government at the same time. 
For the sake of comparison, we have also quoted another article following a similar pattern, Example 15.c, although in this case the actor is not the British Prime Minister, but the President of the European Commission. Here, his words are presented as a threat to Britain's independence as a nation. Accordingly, the response from the Conservative Party, again through $\mathrm{Mr}$ Ancram, is more acrimonious. However, the writer reproduces $\mathrm{Mr}$ Prodi's speech directly and, if we read it attentively, we realize that although he uses tough words to refer to the deadend caused by Britain in the debate, there are no direct threats, nor does he mention that the UK might have to abandon the Union. Consequently, $\mathrm{Mr}$ Ancram's words represent his own interpretation of Mr Prodi's. The text producer has made a very clear choice: Mr Ancram's interpretation is used as the conclusion to the article.

The last text quoted above reproduces again the same pattern, with an opening paragraph presenting the constitutional issue and a second storyline in which the Conservatives are provided with primary voice through direct speech. The difference with respect to the previous articles lies in the fact that the reported event portrays a weakened Britain, thanks to the "vocabulary of failure", thanks to choices like "softened" and "prepared to abandon", which reinforce the view that the British government has yielded to other European powers. Even the use of "precipitate" is evaluative since The Times has been reporting for months on the obstacles to reach an agreement. Therefore, "precipitate" can hardly reflect the actual situation accurately, but it clearly contributes to the characterization of the government in a rather negative light. The article concludes with a direct quotation of the Tory leader, who appropriates himself of the views of his compatriots with respect to the treaty by using "we" the British when, in fact, he means "we" the Conservatives.

\subsection{Opinion articles, editorials and sketches}

These texts are particularly interesting as regards linguistic features, structuring, use of argumentation strategies and content, but it is also true that the ideological component can be regarded as inherent, whereas the manipulation strategies used in more factual reports tend to be concealed within their informative content. As Fowler states, this type of articles seems to attempt to "partition the opinion component of the paper" (1991: 208). This subsection aims to explore whether "opinion articles" can, in fact, be separated from "informative texts" within the same news medium (with one notable exception) and, decide, therefore, on whether all the texts examined in this paper respond to the same editorial policy of dependence on certain ideological presuppositions. Let us consider now four extracts:

16.c THE Prime Minister came to the Commons yesterday to make a dramatic U-turn on a referendum about the EU constitution. It promised to be like watching those programmes that show drivers reversing up the M25 (...) Mr Blair looked most uncomfortable as he 
stood at the dispatch box and removed the mini-clip from his seven-page statement. I hope, for his own sake, that he did not write what followed. He began by patronising us about the constitution, moved on to ridicule the Opposition about peddling myths on bendy bananas, and ended with a sermonette on our destiny.

17.c. Maybe such a policy is indeed racist; maybe it isn't. The VB itself, which has much in common with the Fortuyn List in the Netherlands, has been accused of this. But in a democracy, surely, that is a decision which voters should make, not judges.

18.c. We are reluctant to make up our minds, and doubt that we have to. Secretly, we know the attractions of a Euro-blur. The ambiguity of the British people towards European integration is not careless, but studied.

19.c. I HAVE ALWAYS been conscious of the long-term impact of the great dates of history (...) Perhaps some future British government will make April 20 a national holiday in honour of Tony Blair's great U-turn. It could be called a National Day of Independence.

The nations retain their liberty. The British view stops short of transferring ultimate sovereignty to Brussels. All the major British parties are now committed to a constitutional referendum if one is needed. The British will always vote for their own democratic model.

As can be seen, these opinion articles try to expose the frailty of the British government, the distinctiveness of the British nation, the aggressive nature of Brussels and other European nations, the difficulties posed by the accession of the new countries, that is, text producers are inclined to show a strong opposition to the European issue as a whole. In the four examples quoted above, the function of the text producers is instrumental in projecting a one-sided picture of the Prime Minister, the Labour cabinet and their policy on Europe. In 19.c the writer uses powerful metaphors to position Tony Blair at the centre not only of a political change, but a morally reprehensible one as well. What the newspaper has repeatedly described as a "U-turn" or a " $360^{\circ}$ spin" in order to create the myth of political instability is presented here in a more negative light. The writer equates this change to an extremely dangerous (as well as illegal) car manoeuvre in the middle of a motorway. The comparison is so powerful that it manages to evoke images of speedobsessed drivers who often end up as criminals as a result of their driving habits. Some readers might interpret this as a clear instance of manipulation: however pungent the image can be, it is also true that it does not represent the reality of the months of negotiations on the treaty or the reasons for $\mathrm{Mr}$ Blair's change on the need to call a referendum. But it is also true that the comparison used is a discursively destructive tool, readily complemented with the choice of the "vocabulary of aggression" allegedly used by the Prime Minister: we are told that he patronized, ridiculed and delivered a sermonette. This presentation of $\mathrm{Mr}$ Blair is by no means isolated. The political side is intertextually complemented with personal references of no real political consequence, as when Ann Treneman writes a text entitled "Constitution is just a stroll in the park":

31.c. TONY BLAIR held his monthly press conference yesterday. These events offer the chance to see $\mathrm{Mr}$ Blair close up and he looked better than he has in ages. He has been at the Grecian 2000 again and is back to his natural mousey brown with just a few grey 
edges. His face has been warmed up, either by the Bermuda sun or a splodge of medium beige foundation. (Or, most probably, both).

The cautious text consumer should attempt to perceive the underhand tactics used by the producer. In an opening paragraph like this, which is presented as a "parliamentary sketch", the reader should be alert as the rhetorics of sarcasm supplant a better-informed view of parliamentary events. The perverse comments about Mr Blair's appeareance (including the very negative modifier "mousey") and the reference to his Caribbean holiday muddle up private and public life in a style more characteristic of the tabloids than of a quality newspaper. This is, indeed, a trap the writer has fallen into: the conversationalization strategy, which we have already mentioned in other examples, turns into a strategy of vulgarization, offering serious shortcomings to her ensuing comments on political issues. This type of texts offers a good example of the asymmetrical relationship between text producers and consumers (Clark \& Ivanic 1997: 172) inasmuch the former impose (even force) their evaluative comments on fundamental issues onto their readership, strangling any expressions of dissent, any attempts to re-interpret what is being fed to them.

Extracts 17.c and 18.c offer, in contrast, two examples of what Fowler calls "leading the people" (1991: 208-221). The second one resorts to the use of inclusive "we", as already discussed, in order to impose the writer's own interpretation on the readers, a function often noted by researchers for this type of strategy (Fowler, 1991: 214; van Dijk, 1997: 206). What is surprising about this text is the assertiveness with which it involves the readers in the mental processes of the writer. The use of "we are reluctant" and "we know" aims to reassure the readers, to encourage them to agree, before ending up with a patronizing sentence that proclaims that "the ambiguity of the British is studied", inferring, thus, that there is no need to give more consideration to the issue.

As for Example 17.c, let us begin by remembering that the headline "I've seen the future: it's scary and Belgian" used conversationalization strategies to attract the readers by using "scare tactics": the message in the main body expands this strategy by referring to an extreme-right party recently banned in Belgium. Paradoxically enough, the text producer could have supported his view by mentioning another country, Spain, where another marginal party has also been banned, Marxist-Leninist Herri Batasuna, regarded as the political wing of terrorist organization Eta. However, the writer opts to mention the banning of a party accused of racism that, as he acknowledges, has much in common with another Dutch extreme-right party, and most likely, with other European and, therefore, British parties which opposed issues such as immigration. To support his views, he uses strategies that have been identified as characteristic of conservative newspapers (van Dijk, 1996: 94; 1997: 212-223), as in "Maybe it is racist...but in a democracy..."

We conclude this section with a reference to the only overtly pro-European article in the corpus. As can be expected, the following quotations are extracts from Tony Blair's text:

28.c. WHEN Britain achieves one of its long-standing foreign policy goals, you might think 
it would be a time for widespread celebration. But there are some who seem to think that tomorrow's historic expansion of the European Union to include ten new members is something to criticise. I find this deeply puzzling (...)

We need a Europe ready to change to meet the challenges of globalisation - a Europe with a strong social dimension but not one with rules so rigid that it costs jobs rather than creates them.

We need a Europe dedicated to working with all our allies to combat the threat of global terrorism and to protect our freedoms and way of life. That is best achieved by preserving and strengthening the transatlantic alliance. Europe is strongest and most effective as America's partner, not its rival or servant (...)

If Europe's expansion throws up problems we can and will deal with them. But for every disadvantage, there will be many benefits. Tomorrow's expansion of the EU to the East and South is good for Europe and good for Britain.

The article was published to mark the accession of the new member states on May 12004 , but there are clear hints at other challenges of the time. We shall be succinct here because, despite its interest both in textual and discursive terms, it adds very little to the previous discussion. In fact, its main features mark a sharp contrast with the other texts in the corpus: the use of reiterative parallel structures to emphasize his message (paragraphs three and four), the use of transitivity processes to focus on Britain as a positive actor ("Britain achieves"), the use of language of "euphoria" (Dann, 1996: 65) rather than of "failure" ("achieves", "widespread celebration", "strong social dimension") and the use of inclusive "we" for Europeans, not only for Britons (the only instance in the whole corpus). Finally, we should also point out the reference to the relationship between Europe and America, presented as partners in business rather as a servant-master rapport. Mr Blair's alliance with George Bush has been regarded as a failure by many international media, especially after many of the events in Iraq during the year 2004. However, the text producers of the 84 articles selected for this paper never use this case against the Prime Minister. Let us remember that Rupert Murdoch's media have staunchly supported the invasion of Iraq and the American President's policies for the Middle East.

The panorama offered by the articles in this section fits neatly into the general picture of The Times as a medium particularly critical of European policies. The opinions put forward by its commentators are not "personal but social, institutional or political" (van Dijk, 1998: 22). This implies, in fact, that the discursive construction of anti-European sentiment present is all pervasive, whether we are dealing with opinion articles or more factual texts, creating an asymmetrical relationship between text producers and consumers that the latter would find very difficult to resist (Carter \& Nash, 1990: 21).

\section{Final discussion}

In this final section we shall attempt to explore the third dimension of Fairclough's model (2001: 135), which is concerned with the explanation of the discursive strategies identified 
and interpreted in the previous sections. To do this, we need to summarize the most salient points that we have identified in the analysis of the headlines, leads and stories. The Times texts on the European issue, understood in a broad sense, provide us with sufficient evidence to conclude that this news medium uses an almost monolithic approach to European institutions and policies. Texts producers resort to a variety of linguistic and (both intra and inter) textual strategies to discursively construct Europe as a menace for Britain's way of life, to present Tony Blair's cabinet as fragmented and the Conservative opposition as the only alternative to preserve national identity and institutions.

We shall begin with an interpretation of the articles as a whole. This process relies on three elements, schemata, frames and scripts (Fairclough, 2001: 134-137). Schemata represent particular types of activity, frames refer to the subject matter and scripts to the subjects involved in those activities. Text consumers, in this case, newspaper readers, are endowed with particular interpretative procedures connected with their own experience and their ideological assumptions, which would allow them to understand the texts in a particular way. Some overlapping may occur among the three elements, particularly between the first two. For this reason, this discussion will be centred on the scripts and the frames. The former will deal with the traditional relations existing between British citizens and the EU, as portrayed in the articles. The latter relates to what Fairclough calls the topic (2001: 135). Both will form the basis for the explanation stage. We shall omit the first element because the content of the articles that we have studied relied more on the topic and the relations rather than on the activity as such. Both are connected with existing stereotyping about the issues previously discussed.

The likely readers of the Times texts depend on previous views on the European issue to interpret them. This involves the traditionally strong opposition to Brussels, revolving around the stereotype of European beaurocracy and regulations, on the one hand, and the delivery of national sovereignty to a supranational European government, on the other. These assumptions about the future role of Europe in British politics, and vice versa, should not be unalterable. The influence of a Labour government, in principle more pro-European than their Conservative counterparts, together with the alleged connections between the Prime Minister and the owner of The Times could have implied a wider range of voices within this medium, capable of showing the nature of change within the orders of discourse of British politics, the British government and British media. This could, in turn, contribute to alter existing stereotypes about the advantages and disadvantages of stronger links with Europe. However, the articles analysed do not seem to reflect a more flexible approach to EU policies.

Informative articles resort to strategies that present the weak position of the British government, anticipate the problems of immigration and offer previews of more regulations and norms. Opinion articles interpret the information in a belligerent manner projecting partial interpretations of the new EU as a threat to the UK. Following van Dijk (1998: 22), this could be explained by the fact that the opinions put forward by newspapers are not "personal but social, institutional or political". The two groups of texts analysed offer, in our view, complementary approaches to the discursive construction of an anti-European 
sentiment, creating an asymmetrical relationship between text producers and consumers, which the latter would find very difficult to resist (Carter \& Nash, 1990: 21). The texts remain embedded within the opposition to Europe and the readers have no alternative views within this medium, except for the article produced by Mr Blair.

Thus, the study seems to point out that, as far as the European issue is concerned, The Times offers no instances of "creative discourse" signalling changes in Britain's traditional mistrust of European institutions and policies. It may be argued that news media merely rely on representations shared with their own community to produce their texts, but we may also interpret that the Times uses traditional stereotyping, as well as its own power to perpetuate assumptions about what a nation, their nation, should be. No doubt "the mass media have proved to be the most important way of disseminating representations of the nation" (Edensor, 2002: 141).

This tendency to perpetuate ideological assumptions is carried out through the various textual strategies identified: the lexical choices (the persistent use of specific semantic fields, such as the "vocabulary of failure" or "the vocabulary of aggression"), the various processes of modality and transitivity and the structuring may be taken to project certain interpretations of the news events on to the readership (for instance, by giving final prominence to the voice of Conservative leaders). These discourse types (Fairclough, 2001: 134-135) are neatly embedded within an editorial policy whose ultimate aims are:

1. To emphasize the uniqueness of the cultural and political traditions of the UK as a nation, the need to preserve them and to resist the imperialism coming from Brussels, which represents the threat of "central" power. Britain is often depicted as an observer of the power struggles taking place within the EU or as the target of fierce attacks (through the "vocabulary of aggression") of other members.

2. To present the notion of a European superstate as a fiction formed by a number of various governments, which are only concerned with achieving power for their own nations. It is a strategy of fragmentation, aimed at picturing two superpowers, France and Germany, often cooperating to obtain their objectives, and two medium-size nations, Spain and Poland, struggling for their own benefit, whereas smaller countries are rarely considered except to make alliances. On the other hand, Belgium and other countries are presented as artificially created states without much internal cohesion, whereas Britain sets an example of unity. It is certainly disconcerting that, occasionally, texts could be tinged with racist touches, although carefully presented "in the name of democracy".

3. To apply this fragmentation strategy also to the Labour government and Party, signalling Tony Blair's weaknesses to negotiate in the interest of his own nation. He is often pictured as struggling to pursue his own idea of an integrated Europe whereas the British nation seems to be concerned with a different agenda, which would include what is often referred to as "our way of life". Text writers do not have recourse to inclusive "we" except to refer to the UK, but it is never used to include Europeans.

4. To put forward the alienation between the Prime Minister and the nation. This 
functions in favour of the opposition Conservatives, who receive the focus of the texts as a necessary alternative to a governing Labour Party, affected by its two terms in power. Conservative leaders are often associated with strong positions and are presented as the target of contempt and derision by the government.

Therefore, we might wonder how, then, Mr Blair's column (in which he does stress the importance of greater European integration and the need for a European constitutional treaty) has slipped into the general editorial policy of the Times texts. Among the 84 articles analysed there is practically no dissenting voice. Both factual and opinion articles form a carefully organized jigsaw where all the different parts function with one goal: the discursive construction of anti-European sentiment. This apparent conflict between the Prime Minister's article and the rest could be explained as the result of new discourse with respect to the EU, a new approach which would incorporate dissenting voices and gradually effect changes. Or else it could be argued that we are witnessing an institutional struggle between two public orders of discourse, a mass medium, on the one hand, and the current government, on the other. However, the presence of an ideological struggle between $\mathrm{Mr}$ Blair's discourse and the other Times writers can be more aptly understood and justified for two reasons. On the one hand, we have noted that the relationship between Mr Blair, representing the current political establishment in the UK, and the present owner of The Times has been, to say the least, ambivalent (Simpson, 2003: 167-168; Cohen, 2004: 147149). Rupert Murdoch's most popular (and right-wing) tabloid newspaper, The Sun, took everyone by surprise by proclaiming that they supported the Labour Party in the 1995 general election. Mr Blair seems to have had a close relationship with the owner of the News Media Conglomerate ever since. Thus, the announcement of a referendum on the European constitution was followed by speculations that Rupert Murdoch could have lobbied and, therefore, influenced the Prime Minister's decision (see, for example, the information published on the BBConline newspage http://news.bbc.co.uk/1/hi/uk_politics/ 3642395.stm). This could easily explain the publication of Mr Blair's opinion article in the newspaper, probably as a compensation strategy for the $U$-turn in his European stand. This strategy should not necessarily have any disruptive effects on the overall editorial policy of The Times.

On the other hand, this newspaper might be attempting to project some degree of impartiality by allowing pro-European voices to air their views in a country noted for its pro-conservative news media (Clark \& Ivanic, 1997: 33-34). This situation is clearly detrimental to text consumers since, as we have noted, their relationship with text producers is asymmetrical. This unbalanced rapport is deepened by the fact that the one article favouring European integration has been (allegedly) written by the Prime Minister himself, hardly an objective voice on the matter. Therefore, this dissenting voice might function in favour of the all-pervasive anti-European sentiment of The Times. Paradoxically enough, this editorial policy relies on well-grounded feelings of national pride, on a sense of uniqueness of the British as a nation within Europe, which once The Times may have represented. Today this medium belongs to a news conglomerate that holds a hegemonic 
position in the world. Its American (Australian-born) owner has profited from a deregulated international industry, and might well be concerned with the prospects of the much more regulated economic and social policies of an integrated Europe.

\section{References}

Beaugrande, Robert de (2000): "La saga del análisis del discurso". In T. A. van Dijk, ed., $E l$ discurso como escritura y proceso. Barcelona: Gedisa, 67-106.

Bell, Allan (1991): The Language of News Media. Oxford: Blackwell. . (1998): "The discourse structure of news stories". In A. Bell, and P. Garrett, eds., Approaches to Media Discourse. Oxford: Blackwell, 64-104.

Cameron, Deborah (1995): Verbal Hygiene. London: Routledge.

Carter, Ronald and Walter Nash (1990): Seeing Through Language. A Guide to Styles of English Writing. Oxford: Blackwell.

Chouliaraki, Lilie and Norman Fairclough (1999): Discourse in Late Modernity, Rethinking Critical Discourse Analysis. Edinburgh: Edinburgh University Press.

Clark, Romy and Roz Ivanic (1997): The Politics of Writing. London: Routledge.

Cohen, Nick (2004): Pretty Straight Guys. London: Faber and Faber.

Dann, Graham, M. S (1996): The Language of Tourism, A Sociolinguistic Perspective. Wallingford: CBA International.

Davis, Howard H (1985): "Discourse and media influence". In T. A. van Dijk, ed., Discourse and Communication, New Approaches to the Analysis of Mass Media Discourse and Communication. Berlin/New York: Walter de Gruyter, 44-59.

Edensor, Tim (2002): National Identity, Popular Culture and Everyday Life. Oxford and New York: Berg.

Fairclough, Norman (1992a): "Discourse and text: Linguistic and intertextual analysis within discourse analysis". Discourse and Society 3(2): 193-217. . (1992b): Discourse and Social Change. Cambridge: Polity Press. . (1995a): Media Discourse. London: Arnold. (1995b): Critical Discourse Analysis: the Critical Study of Language. London and New York: Longman. . (1998): "Political discourse in the media: An analytical framework". In A. Bell, and P.

Garrett, eds., Approaches to Media Discourse. Oxford: Blackwell: 142-162. (2001): Language and Power. Harlow: Longman.

Fowler, Roger (1991): Language in the News, Discourse and Ideology in the Press. London: Routledge.

Georgegakopuolou, Alexandra and Goutsos, Dionysis (1997): Discourse Analysis, An Introduction. Edinburgh: Edinburgh University Press.

Gorman, Lyn and David McLean (2003): Media and Society in the Twentieth Century, A Historical Introduction. Oxford: Blackwell.

Halliday, Michael A. K (1985): An Introduction to Functional Grammar. London: Arnold. Halliday, Michael A. K. and Ruqaiya Hasan (1976): Cohesion in English. Harlow: Longman. Hodge, Robert and Gunther Kress (1988): Social Semiotics. Cambridge: Polity Press. Howard, Philip (1985): The State of the Language: English Observed. New York: Oxford 
University Press.

Jucker, Andreas H (1996): “News actor labelling in British newspapers". Text 16 (3): 373-390. McChesney, Robert W (2000): “The Global Media Giants". In R. Andersen and L. Strate, eds. Critical Studies in Media Commercialism. Oxford: Oxford University Press, 59-70.

Simpson, John (2003): The Wars Against Saddam. Taking the Hard Road to Baghdad. London: Macmillan.

Swan, Michael (1995): Practical English Usage. Oxford: Oxford University Press.

van Dijk, Teun A (1990 [1980]): La noticia como discurso: comprensión, estructura y producción de la información. Trans. Guillermo Gal. Barcelona: Paidós.

. (1996): "Discourse, Opinions and Ideologies". In C. Schäffner and H. Kelly-Holmes, eds., Discourse and Ideologies. Clevendon: Multilingual Matters.

. (1997 [1987]): Racismo y análisis critico de los medios. Trans. Montserrat Basté. Barcelona: Paidós.

. (1998): "Opinions and ideologies in the press". In A. Bell, and P. Garrett, eds., Approaches to Media Discourse. Oxford: Blackwell, 21-63.

. (2003): Ideología y discurso. Barcelona: Ariel.

Wodak, Ruth (2003): "De qué trata el análisis crítico del discurso (ACD). Resumen de su historia, sus conceptos fundamentales y sus desarrollos". In R. Wodak, and M. Meyer, eds. Métodos de análisis crítico del discurso. Barcelona: Gedisa, 17-34. 